\title{
Surface Eevaluation of HSQ Containing PDMS Additive after Room-temperature Nanoimprinting
}

\author{
Norihiro Sugano, Makoto Okada, Yuichi Haruyama and Shinji Matsui \\ Graduate School of Science, University of Hyogo, 3-1-2 Koto, Kamigori-cho, Hyogo, 678-1205, Japan
}

Keywords: room temperature nanoimprint, HSQ, PDMS

\section{Introduction}

Nanoimprint lithography (NIL) has a potential to easily fabricate the various nanostructures ${ }^{1-3)}$. A release property of nanoimprint mold is one of important factors in NIL because the mold is in direct contact with a nanoimprint resin. Hence, the mold is usually coated with an antisticking layer (ASL) to prevent the adhesion of resin and the replica mold is also required to reduce damage to the master mold. Recently, the polymer molds have been studying as the replica mold ${ }^{4-8)}$. Hydrogen silsesquioxane (HSQ) is one of spin-on-glasses (SOGs) and is also one of promising replica mold materials because HSQ has high hardness, thermal stability and transparence. HSQ is well known as a high resolution negative-tone electron beam (EB) resist ${ }^{9}$. It was reported that HSQ pattern fabricated by EB lithography was used as the nanoimprint mold ${ }^{10-12)}$. However, a long EB exposure time is needed to make the HSQ pattern. Previously, we reported that the HSQ pattern can be obtained by room temperature (RT) nanoimprinting with a short fabrication time ${ }^{13-32)}$. In RT-nanoimprinting, the mold is pressed to a sol-gel material such as SOG without heating and UV irradiation processes. The HSQ pattern fabrication by RT-nanoimprinting is a useful technique to obtain the HSQ replica mold. To carry out nanoimprinting, the HSQ replica mold is usually coated with ASL because it does not have sufficient release property. If we can fabricate HSQ replica mold with release property by RT-nanoimprinting, ALS coating process on the replica mold is not necessary. So far, to induce release property for HSQ replica mold, we added poly(dimethylsiloxane) (PDMS) additive to HSQ resin and confirmed that water contact angle of spin-coated HSQ with PDMS additive increased after annealing at $300^{\circ} \mathrm{C}^{33)}$. In RT-nanoimprinting, two types of mold are used as master molds, which are $\mathrm{SiO}_{2}$ on $\mathrm{Si}$ hard mold and PDMS soft mold. In this study, we found that the release property of HSQ with PDMS additive imprinted by $\mathrm{SiO}_{2} / \mathrm{Si}$ hard mold was superior to that by PDMS soft mold and, to elucidate the phenomena, evaluated the surfaces of HSQ with PDMS additive after RT-nanoimprinting using $\mathrm{SiO}_{2}$ on $\mathrm{Si}$ hard and PDMS soft molds.

\section{Experimental methods}

HSQ has two different structures of cage and ladder structures. We reported that the imprinted ladder type HSQ pattern was not deformed by annealing ${ }^{27)}$ OCNL103 (TOKYO OHKA KOGYO Co., Ltd) and P7268-DMS (Polymer Source Inc.) were used as a ladder type HSQ and PDMS additive, respectively. To examine the optimized amount of PDMS additive, we made HSQ resins with PDMS additive of $0.1,1$ and 10 $\mathrm{wt} \%$ and carried out RT-nanoimprinting using these resins. We first carried out RT-nanoimprinting using $\mathrm{SiO}_{2}$ on $\mathrm{Si}$ and PDMS molds on HSQ with $0.1,1$ and $10 \mathrm{wt} \%$ PDMS additive to examine whether the HSQ pattern is formed. In the case of using $\mathrm{SiO}_{2}$ on $\mathrm{Si}$ hard mold, the pattern was successfully delineated only when using HSQ with $0.1 \mathrm{wt} \%$ PDMS additive. On the 
other hand, all HSQ with PDMS additive resins could be patterned by using PDMS soft mold. These results indicate that pattern formation by RT-nanoimprinting depend on the mold materials and contents of PDMS additive. So, to evaluate under the same conditions for both $\mathrm{SiO}_{2}$ on $\mathrm{Si}$ and PDMS molds, we used HSQ with 0.1 wt\%-PDMS additive as the resin.

A $\mathrm{SiO}_{2}$ on $\mathrm{Si}$ hard mold was fabricated by $\mathrm{EB}$ lithography and reactive ion etching. Both line and space widths were $500 \mathrm{~nm}$. The master mold was coated with ASL (OPTOOL HD 1100-TH, Daikin Industries, Ltd.) by dip coating process. On the other hand, PDMS soft mold was fabricated by using the $\mathrm{SiO}_{2}$ on $\mathrm{Si}$ mold. SYLGARD184 (Dow Corning Toray Co., Ltd.) was used as a PDMS soft mold material. The fabrication process of the PDMS soft mold was as follows. SYLGARD184 was casted on the $\mathrm{SiO}_{2}$ on Si mold and it was baked at $150{ }^{\circ} \mathrm{C}$ for $10 \mathrm{~min}$. After the baking process, PDMS soft mold was separated from the $\mathrm{SiO}_{2}$ on $\mathrm{Si}$ mold. NM-0901HB (Meisyo Kiko Co.) was used as a nanoimprint apparatus. The nanoimprint condition was different between $\mathrm{SiO}_{2}$ on $\mathrm{Si}$ hard mold and PDMS soft molds. In the case of using $\mathrm{SiO}_{2}$ on $\mathrm{Si}$ hard mold, the imprinting pressure and time were $50 \mathrm{MPa}$ and $180 \mathrm{sec}$, respectively. On the other hand, RT-nanoimprinting using PDMS soft mold was carried out with $0.05 \mathrm{MPa}$ and $180 \mathrm{sec}$.

To evaluate the release property of HSQ with PDMS additive imprinted by $\mathrm{SiO}_{2}$ on $\mathrm{Si}$ and PDMS molds, we measured the water contact angle by using a contact angle meter (Drop Master 500: Kyowa Interface Science Co.). In addition, we examined the surface state of imprinted HSQ with PDMS additive by X-ray photoelectron spectroscopy (XPS) measurements (PHI X-tool, ULVAC-PHI, Inc.). The $\mathrm{Al} \mathrm{K} \alpha$ line $(\mathrm{h} v=1486.6 \mathrm{eV})$ was used as the excitation source and incident angle was $45^{\circ}$. The photoelectron spectra were recorded at an emission angle $45^{\circ}$ to the surface normal.

\section{Results and Discussion}

First, we evaluated the release property of imprinted HSQ with $0.1 \mathrm{wt} \%$-PDMS additive. It is assumed that that the release property is induced by segregation of PDMS additive in HSQ resin. Hence, the annealing temperature is an

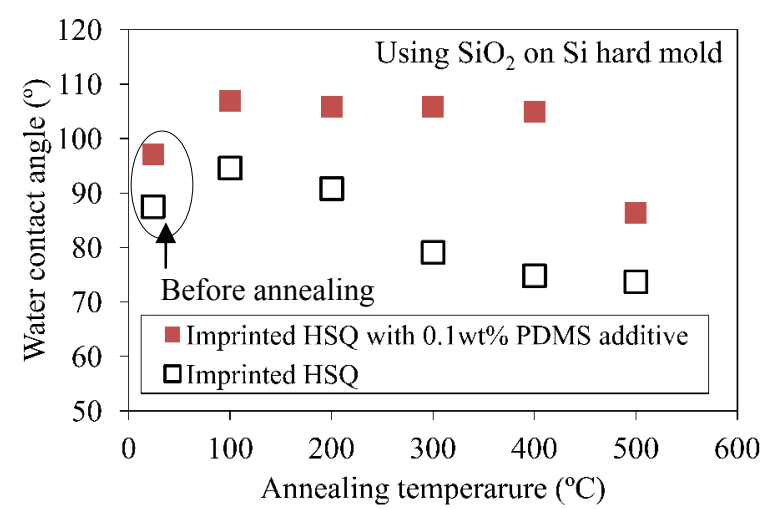

(a)

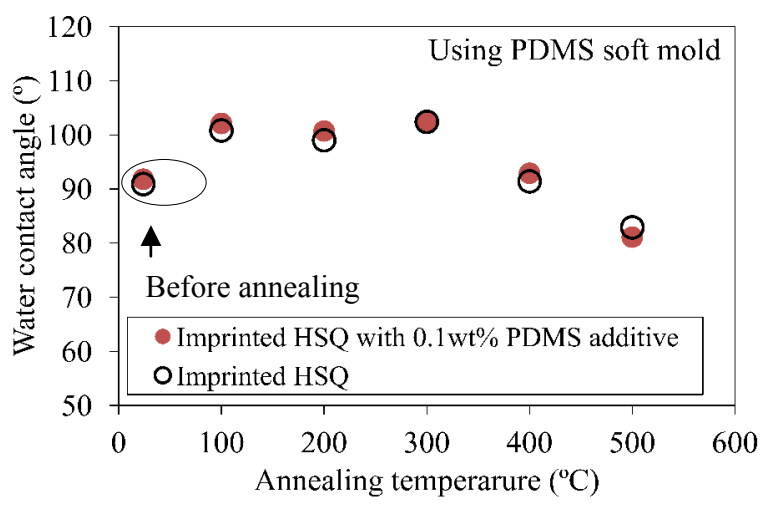

(b)

Fig. 1 Annealing temperature dependence of water contact angle on the flat surfaces of HSQ with and without $0.1 \mathrm{wt} \%$-PDMS additive. The samples were imprinted by using (a) $\mathrm{SiO}_{2}$ on $\mathrm{Si}$ hard and (b) PDMS soft molds.

important factor. We therefore examined annealing temperature dependence of water contact angle on the flat surface of imprinted HSQ with $0.1 \mathrm{wt} \%$-PDMS additive, as shown in Fig. 1. The annealing was carried out at 100, 200, 300, 400 and $500{ }^{\circ} \mathrm{C}$ in a vacuum at $1.0 \times 10^{-3} \mathrm{~Pa}$ for 1 h. In the case of $\mathrm{SiO}_{2}$ on $\mathrm{Si}$ hard mold, the water contact angle of imprinted HSQ with 0.1 wt $\%$-PDMS additive was higher than that of imprinted HSQ without PDMS additive before annealing, as shown in Fig. 1(a). In addition, the water contact angle of imprinted HSQ with $0.1 \mathrm{wt} \%$-PDMS additive was increased by annealing of $100-400{ }^{\circ} \mathrm{C}$, which means the surface segregation occurrence of PDMS additive to the HSQ surface, and the water contact angle at $500{ }^{\circ} \mathrm{C}$ annealing drastically dropped below that 
before annealing due to the decomposition of PDMS additive segregated on the HSQ surface. These results indicated that the PDMS additive induced the release property by annealing of $100-400{ }^{\circ} \mathrm{C}$ when we used $\mathrm{SiO}_{2}$ on $\mathrm{Si}$ hard mold. On the other hand, in the case of using PDMS soft mold, the measurement results showed different trends, as shown in Fig. 1(b). The water contact angles of imprinted HSQ with $0.1 \mathrm{wt} \%$ PDMS additive were almost the same values as those of imprinted HSQ without PDMS additive mold before and after annealing. These results suggest that the mold materials affect to the segregation behavior of PDMS additive in HSQ resin.

Next, to examine the surface states of imprinted HSQ with and without PDMS additive imprinted by using $\mathrm{SiO}_{2}$ on $\mathrm{Si}$ and PDMS molds, we carried out XPS for the HSQ patterns with and without PDMS additive after $300{ }^{\circ} \mathrm{C}$ annealing. The spin-coated HSQ with and without 0.1 wt $\%$-PDMS additive was also analyzed as a reference sample. Figures 2(a), 2(b) and 2(c) show XPS wide scan spectra of HSQ with and without $0.1 \mathrm{wt} \%$-PDMS additive, spin -coated and imprinted by using $\mathrm{SiO}_{2}$ on $\mathrm{Si}$ hard and PDMS soft molds after $300{ }^{\circ} \mathrm{C}$ annealing, respectively. $\mathrm{C} 1 \mathrm{~s}$ peak is due to methyl group in PDMS and was observed in all spectra. It is inferred that the small $\mathrm{C} 1 \mathrm{~s}$ peak in the spectrum of spin-coated HSQ without PDMS additive is caused by contamination.

Figure 3 shows $\mathrm{C} 1 \mathrm{~s}$ regional spectra. The $\mathrm{C} 1 \mathrm{~s}$ peak intensities of spin-coated (Fig. 3(a)) and imprinted HSQ (Fig. 3 (b)) with 0.1\% PDMS additive by using $\mathrm{SiO}_{2}$ on $\mathrm{Si}$ hard mold were larger than those (Fig. 3 (d), (e)) of HSQ without PDMS additive. These results indicate that PDMS additive segregated to the spin-coated HSQ surface and HSQ pattern imprinted by using $\mathrm{SiO}_{2}$ on $\mathrm{Si}$ hard mold by $300{ }^{\circ} \mathrm{C}$ annealing, as illustrated in Figs. 4(a) and 4(b). On the other hand, in the case of using PDMS soft mold, C1s peak intensity (Fig. 3 (c)) in imprinted HSQ with $0.1 \mathrm{wt} \%$ PDMS additive was almost the same as that (Fig. 3 (f)) of imprinted HSQ without PDMS

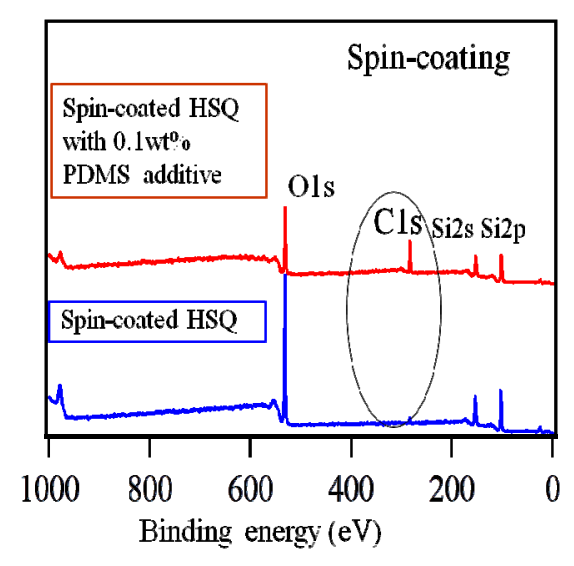

(a)

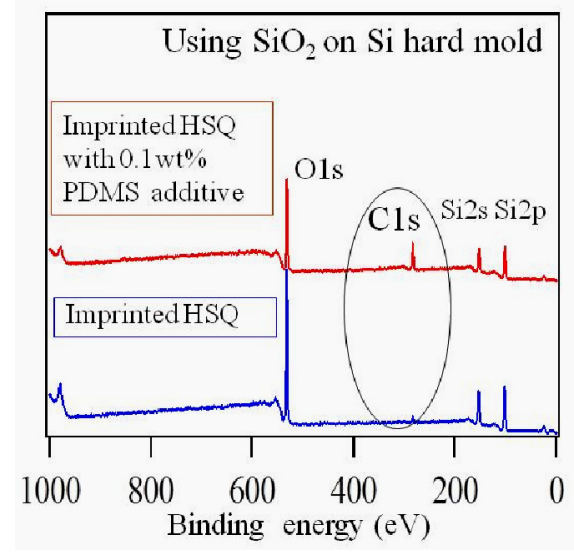

(b)

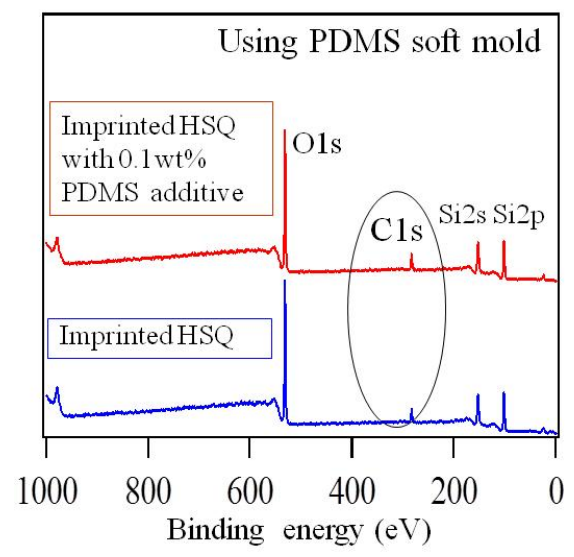

(c)

Fig. 2 XPS wide scan spectra of HSQ with and without $0.1 \mathrm{wt} \%$-PDMS additive after annealing treatment at $300{ }^{\circ} \mathrm{C}$. (a) spin-coated HSQ, HSQ flat patterns imprinted by using (b) $\mathrm{SiO}_{2}$ on $\mathrm{Si}$ hard and (c) PDMS soft molds. 
additive. In addition, the $\mathrm{C} 1 \mathrm{~s}$ peak intensity (Fig. 3 (f)) of HSQ without PDMS additive imprinted by using PDMS soft mold was the highest in the spectra (Figs. 3 (d), (e), (f)) of HSQ without PDMS additive. Furthermore, the $\mathrm{C} 1 \mathrm{~s}$ peak intensity (Fig. 3 (c)) of HSQ with PDMS additive imprinted by using PDMS soft mold was lowest in the spectra (Figs. 3 (a), (b), (c)) of HSQ with PDMS additive.

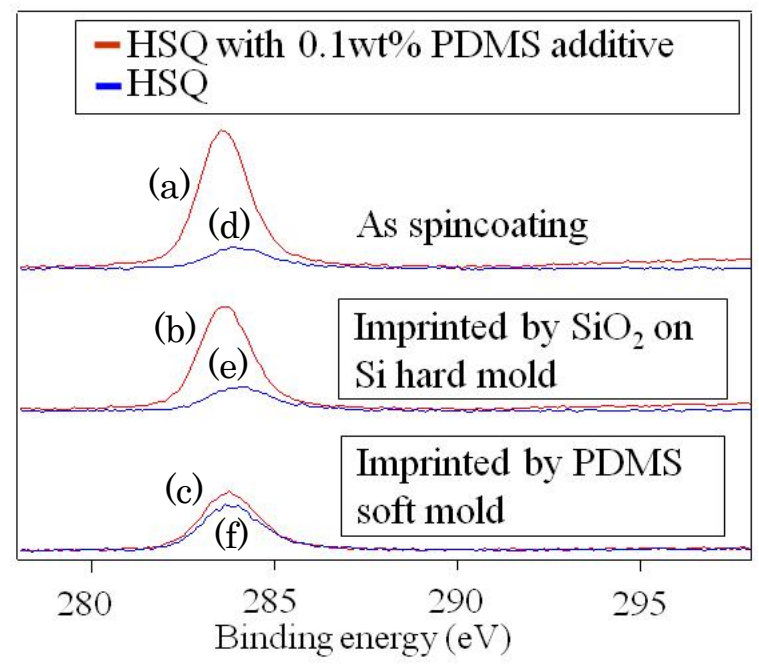

Fig. $3 \mathrm{C} 1 \mathrm{~s}$ regional spectra of HSQ with and without $0.1 \mathrm{wt} \%$-PDMS additive after annealing treatment at $300{ }^{\circ} \mathrm{C}$. Spin-coated HSQ, HSQ flat patterns imprinted by using $\mathrm{SiO}_{2}$ on $\mathrm{Si}$ hard and PDMS soft molds.

These results suggest that PDMS additive was not segregated and partial PDMS material of PDMS soft mold transferred to the HSQ surface and also PDMS additive in HSQ resin was absorbed or attached on PDMS soft mold during RT-nanoimprinting using PDMS soft mold, as illustrated in Fig. 4(c).

To examine the stability of release property of the HSQ with $0.1 \mathrm{wt} \%$-PDMS additive replica molds fabricated by using $\mathrm{SiO}_{2} / \mathrm{Si}$ and PDMS molds with flat surfaces, we carried out thermal nanoimprinting and following $300{ }^{\circ} \mathrm{C}$ annealing, and then measured the water contact angle on the replica molds. NEB-22 (Sumitomo chemical Co., Ltd.) was used as a resin. The imprinting pressure, temperature and time were $10 \mathrm{MPa}, 120^{\circ} \mathrm{C}$ and 1 min, respectively. Figure 5 shows the imprinting time dependence of water contact angle for the

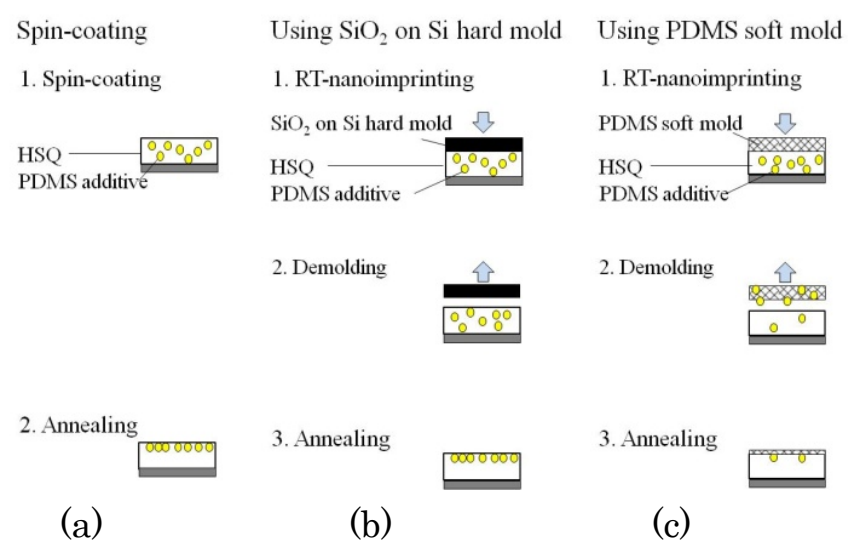

Fig. 4 Segregation schematic of PDMS additive in HSQ resin after RT-nanoimprinting, following annealing. (a) spin-coating, in the case of using (b) $\mathrm{SiO}_{2}$ on $\mathrm{Si}$ hard and (c) PDMS soft molds.

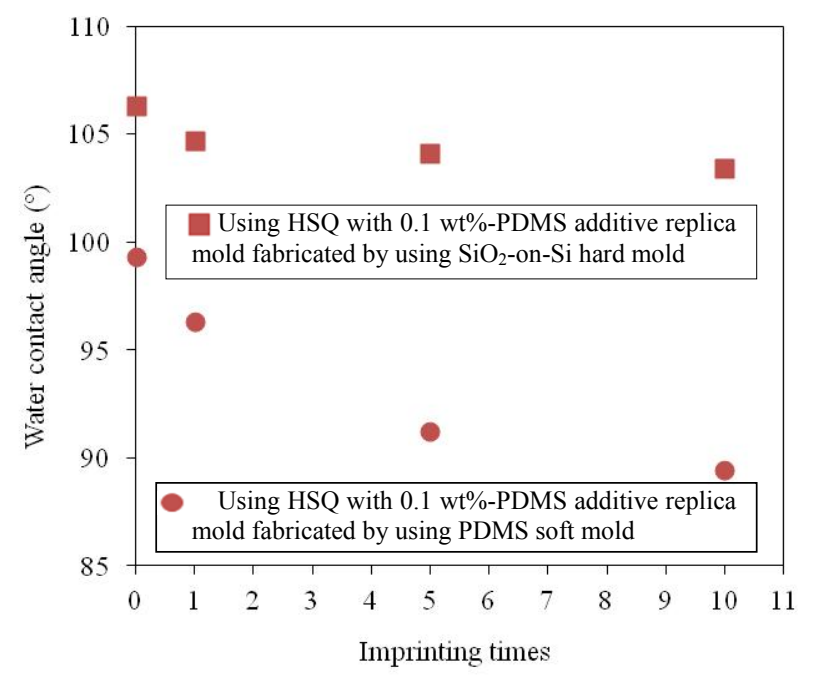

Fig. 5 Imprinting time dependence of water contact angle for HSQ with $0.1 \mathrm{wt} \%$-PDMS additive replica mold after annealing treatment at $300{ }^{\circ} \mathrm{C}$.

HSQ replica molds. The water contact angle of HSQ with $0.1 \mathrm{wt} \%$-PDMS additive replica mold fabricated by using $\mathrm{SiO}_{2}$ on $\mathrm{Si}$ mold was maintained $103^{\circ}$ after 10 imprinting times of thermal nanoimprinting. On the other hand, in the case of using PDMS soft mold, the water contact angle of HSQ with $0.1 \mathrm{wt} \%$-PDMS additive replica mold decreased as the increase of imprinting time and $90^{\circ}$ at 10 imprinting times, which dropped about $10^{\circ}$ compared to that before imprinting. These results can be seen from the experimental data of Fig. 3, that is, PDMS additive was segregated on the surface of HSQ 
with 0.1 wt $\%$-PDMS additive replica mold fabricated by using $\mathrm{SiO}_{2}$ on $\mathrm{Si}$ mold, but not segregated on that by using PDMS mold. We proved from these results that the surface states of HSQ with and without PDMS additive imprinted by RT-nanoimprinting depend on the mold materials.

\section{Conclusion}

We evaluated the surface states of HSQ with $0.1 \mathrm{wt} \%$ PDMS additive replica molds fabricated by RT nanoimprinting using $\mathrm{SiO}_{2}$ on $\mathrm{Si}$ and PDMS master molds by water contact angle and XPS measurements. In the case of using $\mathrm{SiO}_{2}$ on $\mathrm{Si}$ master mold, PDMS additive remained in HSQ after RT-nanoimprinting and segregated to the HSQ surface after annealing treatment, which has a good release property. On the other hand, in the case of using PDMS master mold, it is assumed that almost PDMS additive in HSQ transferred to the PDMS mater mold during RT-nanoimprinting. As a result, the stable release property was not induced. We proved from these results that the segregation of PDMS additive in HSQ replica mold depended on the master mold materials.

\section{Acknowledgments}

The authors thank Prof. Dr. K. Moriwaki, M. Kimura and K. Kitanaka at Kobe University for XPS analysis.

\section{References}

1) S. Y. Chou, P. R. Krauss and P. J. Renstrom, Appl. Phys. Lett., 67 (1995) 3114.

2) S. Y. Chou, P. R. Krauss and P. J. Renstrom, Science, 272 (1996) 85.

3) Haisma, M. Verheijen and K. Heuvel, J. Vac. Sci. Technol. B, 14 (1996) 4124.

4) N. Unno, H. Tamura and J. Taniguchi, Microelectron. Eng., 97 (2012) 72.

5) B. K. Lee, L. Hong, H. Y. Lee, D. Kim and T. Kawai, Langmuir, 25, (2009) 11768.

6) N. B. A. Talip[a]Yusof and J. Taniguchi Microelectron. Eng., 10 (2013) 163.

7) J. Y. Kim, K. Park, Z. Kim, K. Baekb and L. Dob, Soft Matter 8 (2012) 1184.

8) S. Gilles, M. Meier, M. Prömpers, A. Hart and C Kügeler, Microelectron. Eng., 86 (2009) 661.

9) H. Namatsu, Y. Takahashi, K. Yamazaki, T. Yamaguchi, M. Nagase and K. Kurihara, J. Vac.
Sci. Technol. B, 16 (1998) 69.

10) J. Joo, K. Jun and J. M. Jacobson, J. Vac. Sci. Technol. B 25, (2007) 2407

11) Y. Matsubara, J. Taniguchi and I. Miyamoto, $J$. Appl. Phys., 45 (2006) 5538.

12) J. Taniguchi, K. Machinaga, N. Unno and N. Sakai, Microelectron. Eng., 86 (2009) 676.

13) S. Matsui, Y. Igaku, H. Ishigaki, J. Fujita, M. Ishida, Y. Ochiai, M. Komuro, and H. Hiroshima, J. Vac. Sci. Technol. , B19 (2001) 2801.

14) Y. Igaku, S. Matsui, H. Ishigaki, J. Fujita, M. Ishida, Y. Ochia, H. Namatsu, M. komuro, and H. Hiroshima, Jpn. J. Appl., Phys. 41 (2002) 4198.

15) S. Matsui, Y. Igaku, H. Ishigaki, J. Fujita, M. Ishida, Y. Ochiai, H. Namatsui, and M. Komuro, $J$. Vac. Sci. Technol. , B21 (2003) 688.

16) K. Nakamatsu, K. Watanabe, K. Tone, T. Katase, W. Hattori, Y. Ochiai, T. Matsuo, M. Sasago, H. Namatsu, M. Komuro, and S. Matsui, Jpn. J. Appl. Phys. , 43 (2004) 4050.

17) K.Nakamatsu, K. Watanabe, K. Tone, H. Namatsu, and S. Matsui, J. Vac. Sci. Technol., B23 (2005) 597.

18) K. Nakamatsu, K. Tone, H. Namatsu, and S. Matsui, J. Vac. Sci. Technol., B24 (2006) 195.

19) K. Nakamatsui and S. Matsui, Jpn. J. Appl. Phys., 45 (2006) L546.

20) M. Kawamori, K. Nakamatsu, Y. Haruyama, and S. Matsui, Jpan. J. Appl. Phys., 45 (2006) 8994.

21) K. Nakamatsu, K. Ishikawa, N. Taneichi, and S. Matsui, Jpn. J. Appl. Phys., 46 (2007) 5388.

22) K. Nakamatsu, K. Ishikawa, N. Taneichi, and S. Matsui, J. Photopolym. Sci. Technol., 20 (2007) 555.

23) K. Nakamatsu, M. Okada, and S. Matsui, Jpn. J. Appl. Phys., 47 (2008) 8619.

24) Y. Kang, M. Okada, K. Nakamatsu, Y. Haruyama, K. Kanda, and S. Matsui, $J$. Photopolym. Sci. Technol., 22 (2009) 193.

25) Y. Kang, M. Okada, K. Nakamatsu, Y. Haruyama, K. Kanda, and S. Matsui, $J$. Photopolym. Sci.Technol., 22 (2009) 189.

26) Y. Kang, M. Okada, K. Nakamatsu, K. Kanda, Y. Haruyama, and S. Matsui, J. Vac. Sci. Technol., B27 (2009) 2805.

27) Y. Kang, M. Okada, C. Minari, K. Kanda, Y. Haruyama, and S. Matsui, Jpn. J. Appl. Phys., 49 (2010) 06GL13.

28) Y. Kang, M. Okada, K. Kanda, Y. Haruyama, 
and S. Matsui, Proc. of RadTech Asia, Japan, (2011) 36-40.

29) Y. Kang, M. Okada, Y. Nakai, Y. Haruyama, K. Kanda, and S. Matsui, J. Vac. Sci. Technol., B29 (2011) 06FC10.

30) K. Kang, S. Omoto, Y. Nakai, M. Okada, K. Knada, Y. Haruyama, and S. Matsui, J. Vac. Sci. Technol., B29 (2011) 011005.
31) Y. Kang, M. Okada, S. Omoto, Y. Haruyama, K. Kanda, and S. Matsui, J. Vac. Sci. Technol., B29 (2011) 06FC03.

32) Y. Kang, Y. Nakai, Y. Haruyama, and S. Matsui, J. Vac. Sci. Technol., B30 (2012) 06FB06. 33) N. Sugano, M. Okada, Y. Haruyama and S. Matsui, 26th international microprocesses and nanotechnology conference, (2013) 7P-7-99. 